\title{
Knowledge, attitude and practices about cervical cancer screening among nursing staff in rural tertiary care center
}

\author{
Soniya Vishwakarma*, Rajani Rawat, Nupur Mittal, Pragya Shree
}

\begin{abstract}
Department of Obstetrics and Gynecology, Uttar Pradesh University of Medical Sciences, Saifai, Etawah, Uttar
\end{abstract} Pradesh, India

Received: 15 July 2018

Accepted: 06 August 2018

\section{*Correspondence:}

Dr. Soniya Vishwakarma,

E-mail: soniyaramesh17@gmail.com

Copyright: (C) the author(s), publisher and licensee Medip Academy. This is an open-access article distributed under the terms of the Creative Commons Attribution Non-Commercial License, which permits unrestricted non-commercial use, distribution, and reproduction in any medium, provided the original work is properly cited.

\begin{abstract}
Background: Cervical cancer is the second most common cancer among women worldwide. The knowledge and attitude of nursing personnel towards cervical cancer screening can grossly influence the community. As the doctor to patient ratio is low in India, staff nurses if trained can act both as health educators and service providers. Objectives of the study were to determine the baseline information about the knowledge of cervical cancer and explore attitude and practice of Pap smear screening among staff nurses.

Methods: In this cross-sectional study sample of 100 nurses was selected randomly out of the total 445 nurses employed in the hospital at a rural tertiary care centre from August 2016 to October 2016. A self-administered, structured, open ended and pretested questionnaire comprising of questions on the general characteristics, awareness, perceptions and actual practices of nursing personnel was used to gather information about cervical screening.

Results: In this study, $82 \%$ knew that Pap smear can detect cancer. About $48 \%$ knew that it can present as postmenopausal bleeding and $32 \%$ of the respondents knew that HPV is a risk factor for cancer cervix, but only $30 \%$ knew about HPV vaccine and only $35 \%$ have ever been screened.

Conclusions: The study showed that, knowledge about cancer cervix, screening and practice of Pap smear is low among nursing staff. There is an urgent need for integration of cervical cancer prevention issues in the nurses existing training curriculum.
\end{abstract}

Keywords: Attitude, Cervical cancer, Knowledge, Screening

\section{INTRODUCTION}

Worldwide, cervical cancer is the second most common $(12 \%)$ cancer in women, however, in developing countries; it is the most common cancer among women. ${ }^{1}$ According to the International Agency for Research on Cancer (IARC), and India has the highest number of cervical cancer cases in the world. There are an estimated 1,32,000 new cases and 74,000 deaths each year which occur due to cervical cancer in India. ${ }^{2}$ India bears about one fifth of the world's burden of cervical cancer, and $>100,000$ new cases are detected every year in India, which causes $20 \%$ of all female deaths in India., Cervical cancer and its mortality have been proven preventable by various screening and treatment strategies aimed at sexually active women.

The key to reducing cervical cancer morbidity and mortality is early detection and treatment of cervical precancerous lesions among sexually active women on universal basis with available protocols for screening. Precancerous lesions are detectable for 10 years or more before cervical cancer develops. Among all malignant tumours, cervical cancer is the one that can be most 
effectively controlled by organized screening programs. ${ }^{5}$ An organized screening program can reduce incidence and mortality by $80 \%$ as shown in developed countries. ${ }^{6}$ Pap smear is one of the modern success stories in the field of preventive medicine which detects cervical cancer in its early stage. In 1943, Dr George Papanicolau introduced this technique. ${ }^{7}$ Other methods of screening technique are colposcopy, visual inspection with acetic acid (VIA), visual inspection with lugols iodine (VILI), and Human Papilloma Virus (HPV) DNA testing. ${ }^{8-10}$

In India also, both early detection and screening remains a major area of concern coupled with poor literacy and low level of awareness amongst Indian women. As the doctor to patient ratio is low in India, thus if staff nurses trained can act both as health educators and service providers. Staff nurses are the personnel who can help in spreading awareness regarding this problem in the target population. To have a successful cancer control program, nursing staff must be aware of facts about cervical cancer and screening tests themselves. With this background the present study was conducted to assess the level of knowledge and attitude regarding cervical cancer screening among nursing staff.

\section{METHODS}

This study was descriptive cross-sectional study which has been conducted in tertiary care rural institute of Uttar Pradesh i.e., Uttar Pradesh University of Medical Sciences (UPUMS), Saifai from August 2016 to October 2016. A sample of 100 nurses was selected randomly out of the total 445 nurses employed in the hospital at that time.

\section{Inclusion criterion}

- The staff nurses who agreed to participate and gave consent.

\section{Exclusion criterion}

- Staff nurses who were not willing to participate in the study.

The staff nurses who agreed to participate were given a consent form along with a predesigned, pretested, selfadministered multiple response questionnaires with open ended questions. With the help of a predesigned and pretested questionnaire, information was collected regarding demographic profile, knowledge about cervical cancer screening and attitude towards screening techniques among the nursing staff of hospital.

The participants were required to mark their responses against the appropriate answers on the questionnaire sheet. The anonymity and confidentiality of the participants were taken care of and the collected data were maintained. The obtained data were entered and analysed by using statistical package for social sciences (SPSS) software version 21.

\section{RESULTS}

Among the respondents, the age group of 26 to 30 years formed the largest with $50 \%$ of them belonging to this age group and $60 \%$ of the respondents were from 20 to 25 yr. of age at first time sexual intercourse. $88 \%$ of the participants were married and about and $50 \%$ of the participants had 2 children (Table 1).

Table 1: Demographic profile.

\begin{tabular}{|l|l|}
\hline Demographic profile & \multicolumn{1}{l}{$\mathbf{n = 1 0 0}(\%)$} \\
\hline Age & \\
\hline $20-25$ years & $26(26 \%)$ \\
\hline $26-30$ years & $50(50 \%)$ \\
\hline $31-35$ years & $20(20 \%)$ \\
\hline $36-40$ years & $4(4 \%)$ \\
\hline Age at first sexual intercourse \\
\hline$<20$ years & $6(6.8 \%)$ \\
\hline $20-25$ years & $60(68.2 \%)$ \\
\hline $26-30$ years & $22(25 \%)$ \\
\hline Marital status & \\
\hline Married & $88 \%$ \\
\hline Unmarried & $22 \%$ \\
\hline Religion & $74 \%$ \\
\hline Hindu & $10 \%$ \\
\hline Muslim & $16 \%$ \\
\hline Christian \\
\hline
\end{tabular}

In this study $94 \%$ knew that cancer cervix is preventable and $82 \%$ knew that Pap smear can detect cancer, whereas only $32 \%$ knew that cervical cancer can be detected even before symptoms appear. $52 \%$ were aware that Pap smear is used as screening modality. Very few participants $12 \%$ were aware of VIA and VILI (Table 2).

Table 2: Knowledge regarding risk factors of cervical cancer.

\begin{tabular}{|l|l|}
\hline Questions related to knowledge & Responded yes \% \\
\hline HPV infection & 32 \\
\hline HPV vaccination for prevention & 30 \\
\hline Sexual intercourse at early age & 18 \\
\hline Smoking & 24 \\
\hline More than one sexual partner & 36 \\
\hline Multiparity & 42 \\
\hline Family history of cervical cancer & 30 \\
\hline
\end{tabular}

Only $18 \%$ knew that the cancer cervix can present without any symptoms. About $48 \%$ knew that it can present as post-menopausal bleeding and $42 \%$ were aware that it can present as abnormal uterine bleeding, but only $44 \%$ knew that it can even present as post coital bleeding. $50 \%$ of the respondents stated that it can present with foul smelling discharge (Table 3). 
The risk factors like starting sex at an early age, having many sexual partners and multi parity were known to 30 to $40 \%$ of the respondents. $32 \%$ of the respondents knew that HPV is a risk factor for cancer cervix, but only $30 \%$ knew about HPV vaccine (Table 4).

Table 3: Knowledge regarding symptoms of cervical cancer.

\begin{tabular}{|ll|}
\hline Knowledge regarding & Responded as yes \% \\
\hline symptoms of cervical cancer & 6 \\
\hline Don't know & 6 \\
\hline No symptoms & 18 \\
\hline Vaginal discharge & 50 \\
\hline Post coital bleeding & 44 \\
\hline Post-menopausal bleeding & 48 \\
\hline Abnormal uterine bleeding & 42 \\
\hline Abdominal pain & 46 \\
\hline
\end{tabular}

Table 4: Knowledge related to cervical cancer screening.

\begin{tabular}{|ll|}
\hline $\begin{array}{l}\text { Knowledge related to } \\
\text { cervical cancer screening }\end{array}$ & Responded as yes \% \\
\hline $\begin{array}{ll}\text { Is cervical cancer preventable } \\
\begin{array}{l}\text { Cervical cancer can be detected } \\
\text { even before symptoms appear }\end{array}\end{array}$ & 94 \\
\hline $\begin{array}{l}\text { Have you ever heard about } \\
\text { pap smear }\end{array}$ & 82 \\
\hline $\begin{array}{l}\text { Pap smear can be used as: } \\
\text { Screening modality }\end{array}$ & $52(63.4 \%)$ \\
\hline Screening and treatment & $14(17.1 \%)$ \\
\hline Don't know & $16(19.5 \%)$ \\
\hline Aware of VIA or VILI & 12 \\
\hline
\end{tabular}

About $46 \%$ participants knew that screening should begin at 21 years or within 3 years of starting of sexual activity, whichever is earlier. About $64 \%$ of the participants thought that every woman is to be screened after 30 years of age, whereas overall $83.8 \%$ of the respondents agreed that all married women should be screened for cancer cervix at least once in a lifetime. Only $20 \%$ knew that Pap smear should be done on yearly basis (Table 5).

Table 5: Knowledge related to cervical cancer screening age and duration.

\begin{tabular}{|l|l|}
\hline Screening should be started at & $\begin{array}{l}\text { Responded as } \\
\text { yes \% }\end{array}$ \\
\hline $\begin{array}{l}\text { More than } 21 \text { years or within } 3 \\
\text { years of starting sexual activity }\end{array}$ & 46 \\
\hline Age> 30 years & 64 \\
\hline Age $>40$ years & 20 \\
\hline How often do you think pap test to be repeated \\
\hline No idea & 42 \\
\hline 6 monthly & 8 \\
\hline 1 yearly & 20 \\
\hline 3 yearly & 12 \\
\hline
\end{tabular}

The attitudes about Pap smear screening showed that about $64 \%$ of the staff nurses thought that Pap smear testing is a doctor's procedure. About $52 \%$ respondents stated that they should undergo cervical screening, but only $35 \%$ have ever been screened (Table 6 ).

Table 6: Attitude towards cervical screening.

\begin{tabular}{|l|l|}
\hline $\begin{array}{l}\text { Questions related to attitude } \\
\text { Do you think that Pap smear } \\
\text { testing is a doctor's procedure }\end{array}$ & 64 \\
\hline $\begin{array}{l}\text { Do you think you should } \\
\text { undergo cervical screening }\end{array}$ & 52 \\
\hline $\begin{array}{l}\text { Do you think all women should } \\
\text { undergo cervical screening }\end{array}$ & 56 \\
\hline Have you ever been screened & 35 \\
\hline
\end{tabular}

Regarding practice of Pap smear screening, only $46 \%$ ever recommended any women to undergo screening for cervical cancer. Out of $65 \%$ non-screened respondents, about 44 respondents stated that they did not get Pap smear because they had no symptom, while 15 stated that they feel shy to get screened. (Table 7).

Table 7: Practice of Pap smear among nursing staff.

\begin{tabular}{|l|l|}
\hline $\begin{array}{l}\text { Pattern of utilization of cervical } \\
\text { screening }\end{array}$ & $\begin{array}{l}\text { Responded as yes } \\
\%\end{array}$ \\
\hline $\begin{array}{l}\text { Have you ever recommended any } \\
\text { women to get cervical cancer } \\
\text { screening done }\end{array}$ & 46 \\
\hline $\begin{array}{l}\text { Have you undergone cervical } \\
\text { screening }\end{array}$ & 35 \\
\hline Cause of not getting yourself screened \\
\hline No knowledge & 18 \\
\hline No symptoms & 44 \\
\hline No time & 21 \\
\hline Embarrassment & 15 \\
\hline Not advised & 23 \\
\hline
\end{tabular}

\section{DISCUSSION}

In this study age group of 26 to 30 years formed the largest with $50 \%$ of them belonging to this age group, this is similar to Bhatija GV et al. ${ }^{11}$ In present study $82 \%$ of respondents knew that Pap smear can detect cancer cervix, which is comparable to the study by Shah V et al where $88.4 \%$ knew and $83 \%$ of respondents knew in a study by Mutyaba et al. ${ }^{12,13}$ About $18 \%$ of the respondents agreed that cancer cervix can present without any symptom, whereas only $13.3 \%$ were aware about it in a study by Shashank et al. ${ }^{14}$ About $48 \%$ in present study knew that cancer cervix can present as post-menopausal bleeding or irregular menstrual bleeding, which is less to study by Shashank et al where this fact was known to $69 \% .{ }^{14}$ About $44 \%$ of the respondents agreed that cancer cervix can present as post coital vaginal bleeding, which is comparable to $46 \%$ in a study by Urasa et al. ${ }^{15}$ 
The analysis of risk factors, revealed that starting sex at early age, having many sexual partners and multi parity known to $30-40 \%$ of the respondents, which is less in comparison to $70 \%$ in the study by V Shah et al. ${ }^{12} 32 \%$ of the respondents in present study, knew that HPV infection is a risk factor for carcinoma cervix, whereas this awareness was noted in $54.1 \%$ in the study by Singh E et al. ${ }^{16}$

When enquired in to screening practices, $46 \%$ in present study knew that it should begin at 21 years or 3 years within starting of sexual activity, whichever is earlier, which is comparable to $54.1 \%$ in the study by Singh E et al. ${ }^{16}$

About $64 \%$ thought that every woman to be screened after 30 years of age in present study, whereas only to $55.5 \%$ have agreed for the same in the study by Urasa et al. ${ }^{15}$ Above $64 \%$ of the respondents in present study, thought that Pap test is a doctor's procedure which is comparable to $71 \%$ in the study by Shashank et al. ${ }^{14}$

When authors enquired in to practices like performing vaginal examination, $46 \%$ of the respondents agreed to have practised, whereas only $53 \%$ practised in the study by Singh E et al. ${ }^{16}$ In present study about $35 \%$ of the staff nurses had themselves undergone Pap testing, whereas $19 \%$ in the study by Mutyaba et al and $46.4 \%$ in the study by Gulertem et al had undergone Pap testing. ${ }^{13,17}$

\section{CONCLUSION}

Knowledge about cancer cervix, screening and practice of Pap smear is low among nursing staff. Despite knowledge of the gravity of cervical cancer and prevention attitudes and practices among nurses towards cervical cancer screening were negative. There is an urgent need for integration of cervical cancer prevention issues in the nurses existing training curriculum.

\section{Recommendations}

Hence it is recommended that routine training in the form of lecture, seminar of the entire health care provider to be done on regular basis or done as a part of the orientation program to newly employed nursing staff. This will give an opportunity to make women more aware, comfortable and confident for screening tests. Moreover, if nurses themselves undergo screening test regularly, they can be role models for the other females.

\section{ACKNOWLEDGMENTS}

Authors are extremely thankful to all the participants for their valuable contribution to carry out this study.

\section{Funding: No funding sources} Conflict of interest: None declared

Ethical approval: The study was approved by the Institutional Ethics Committee

\section{REFERENCES}

1. Standard \& Guidelines, Cervical and breast cancer screening by VIA \& CBE. New York: The United Nations Population Fund; 2006. Available at: web2.unfpa.org>about>docDownload.

2. Laikangbam $P$, Sengupta $S$, Bhattacharya $P$, Duttagupta C, Dhabali Singh T, Verma Y, et al. A comparative profile of the prevalence and age distribution of human papillomavirus type 16/18 infections among three states of India with focus on northeast India. Int J Gynecol Cancer. 2007;17:10717.

3. International agency for research on cancer. Latest world cancer statistics global cancer burden raises to 14.1 million new cases in 2012: Marked increase in breast cancers must be addressed. GLOBOCAN 2012, World Health Organization Press release, 12th December 2013. Available at: http:// www.iarc.fr/en/mediacentre/pr/2013/pdfs/pr223_E.pdf.

4. Shanta V. Perspectives in cervical cancer prevention in India, The international network for cancer treatment and research; 2003. Available at: http://www.inctr.org/meetings/pastmeetings/annualmeeting-2003/.

5. Arbyn M, Rebolj M, De Kok IM, Fender M, Becker $\mathrm{N}$, O'Reilly M, et al. The challenges of organising cervical screening programmes in the 15 old member states of the European Union. Eur $\mathrm{J}$ Cancer. 2009;45:2671-8.

6. Anttila A, Pukkala E, Söderman B, Kallio M, Nieminen P, Hakama M. Effect of organised screening on cervical cancer incidence and mortality in Finland, 1963-1995: recent increase in cervical cancer incidence. Int J Cancer. 1999;83:59-65.

7. Papanicolaou GN. A new procedure of staining vaginal smear. Sci. 1942;95:488.

8. O'Neal R. Cancer-stricken farrah fawcett weighs 86 pounds: Redmond O'Neal. USA: 2009. Available at: www.thaindian.com/.../cancer-strickenfarrahfawcettweighs-86-pounds-redmondoneal_100181396.html.

9. Hand book on cancer. IARC 2003. Available from: www.iarc.fr/en/media-centre/pr/2003/index.

10. Dillner J, Rebolj M, Birembaut P, Petry KU, Szarewski A, Munk C, et al. Long term predictive values of cytology and human papillomavirus testing in cervical cancer screening: joint European cohort study. BMJ. 2008; 337:a1754.

11. Bathija GV, Mallesh S, Gajula M. A study on awareness of cervical cancer among women of reproductive age group in urban slums of old Hubli, Karnataka, India. Int $\mathbf{J}$ Community Med Public Health. 2016;3:2579-83.

12. Shah V, Vyas S, Singh A, Shrivastava M. Awareness and knowledge of cervical cancer and its prevention among the nursing staff of a tertiary health institute in Ahmedabad, Gujarat, India. e Cancer Med Sci. 2012;6. 
13. Mutyaba T, Mmiro FA, Weiderpass E. Knowledge, attitudes and practices on cervical Cancer screening among the medical workers, Uganda. BMC Med Edu. 2006;6:13.

14. Shashank S, Sharma C, Thakur S, Raina N. Cervical cancer screening, KAP among nursing staff in a tertiary level instituition of rural India. Asian Pacific J Canc Prevent. 2013:14,3641-5.

15. Urasa M, Darj E. Knowledge of cervical cancer and screening practices of nurses at a regional hospital in Tanzania. African Health Sci. 2011;1:48-57.

16. Singh E, Seth S, Rani V, Srivastava DK. Awareness of cervical cancer screening among nursing staff in a tertiary institution of rural India. J Gynecol Oncol. 2012;23:141-6.

17. Ertem G. Awareness of cervical cancer risk factors and screening behaviour among nurses in a rural region of Turkey. Asian Pac J Cancer Prev. 2009 Jan $1 ; 10(5): 735-8$.

Cite this article as: Vishwakarma S, Rawat R, Mittal N, Shree P. Knowledge, attitude and practices about cervical cancer screening among nursing staff in rural tertiary care center. Int J Reprod Contracept Obstet Gynecol 2018;7:3796-800. 